\title{
Numerical Evaluation of Settlement trough Width Parameter
}

\author{
Chee Min Khoo ${ }^{1, *}$, Nur Illia Shuhadah Idza Idris², Hisham Mohamad², and Ahmad Shukri \\ Abdul Rashid ${ }^{2}$ \\ ${ }^{1}$ Mass Rapid Transit Corporation, Planning \& Design Department, 50490 Kuala Lumpur, Malaysia \\ ${ }^{2}$ Universiti Teknologi PETRONAS, Civil and Environmental Engineering Department, 32610 Seri \\ Iskandar, Perak
}

\begin{abstract}
Construction of tunnel results in ground movements with a settlement trough which is well described by a Gaussian distribution curve. For near surface settlements, it was established that the trough width $i$ is an approximately linear function of the tunnel depth $z_{o}$ in relation to a trough width parameter $K$ and broadly independent of tunnel construction method and tunnel diameter (except for very shallow tunnels where the cover to diameter ratio is less than one). The choice of an appropriate value of $K$ may require some judgement, since it depends on whether the ground is primarily cohesive or frictional. Published literatures recommended that for practical purposes $K$ could be taken as 0.5 for tunnels in clays and 0.25 for tunnels in sands and gravels. This paper discusses the evaluation of trough width parameter which has not been studied much for typical soil types encountered in the Klang Valley of Malaysia (e.g. Kenny Hill formation weathered materials, granitic soil, alluvium, etc.) of which are commonly in cohesive-frictional nature. The main objective of study is to investigate, using numerical method, the arbitrary relationship of the trough width parameter for different soil types in terms of its effective shear strength parameters and stiffness parameter. A parametric study was carried out to identify parameter(s) which have a significant influence on the settlement trough width and simple equation is presented subsequently for estimating appropriate $K$ values for empirical calculation. This study has excluded two-layered system of different geology where, for example, a tunnel in Kenny Hill formation is overlain by significant thickness of alluvium deposits. Preliminary findings based on numerical analysis showed some promising results. Effort to continually build up the field database to further refine the deduced relationship for the surface settlement trough width parameter is in progress over the course of construction for Klang Valley MRT tunnels.
\end{abstract}

* Corresponding author: khoo.cheemin@mymrt.com.my 


\section{Introduction}

Since the work by Marto in 1958 [1] on field observations of settlements above mine openings and subsequently many other researches [2-3] have shown that the transverse settlement developing at near surface immediately following tunnel construction is welldescribed by a Gaussian distribution curve. O'Reilly and New [4] showed that the trough width $i$ is an approximately linear function of the tunnel depth $z_{o}$ in relation to a trough width parameter $K$ and broadly independent of tunnel construction method and tunnel diameter (except for very shallow tunnels where the cover to diameter ratio is less than one). The validity of the proposed simple approximate relationship of $i=K z_{o}$ was generally confirmed by Rankin [5] for a wide variety of tunnels and for most soil types from around the world. The trough width parameter $K$ is a key parameter, it depends principally on the type of ground whether is primarily cohesive or frictional. Published literatures [4-7] recommended that for practical purposes $K$ could be taken as 0.5 irrespective whether of the tunnel is in soft or stiff clays and 0.25 for tunnel in sands and gravels; the database for tunnels in sands was confined to shallow tunnels with depths to axis level in the range 6$10 \mathrm{~m}$.

This paper discusses the evaluation of trough width parameter which has not been studied much for typical soil types encountered in the Klang Valley region in Malaysia (e.g. weathered materials from the Kenny Hill meta-sedimentary formation, granitic soil, alluvium, etc.) of which are commonly in cohesive-frictional nature. The main objective of study is to investigate, using numerical method, the arbitrary relationship of the trough width parameter for different soil types in terms of its effective shear strength parameters and stiffness parameter. A parametric study was carried out to identify parameter(s) which have a significant influence on the settlement trough width. Following the study, simple equation has been developed for estimating appropriate $K$ values for empirical calculation of tunnelling-induced settlement using the Gaussian function. This study has excluded twolayered system of different geology where, for example, a tunnel in Kenny Hill formation is overlain by significant thickness of alluvium deposits.

\section{Application of theory to settlement analysis}

The empirical formulation commonly used in engineering practice for estimation of tunnelling-induced ground settlements is developed by Schmidt [2] and Peck [3]. Peck [3] assumed that the transverse ground settlement trough can be reasonably represented by a Gaussian distribution curve - an idealisation which has considerable mathematical advantages. Two parameters, namely the ground loss $V_{l}$ (sometimes referred to as volume loss) and the point of inflection $i$ of the curve, are needed to fit the surface settlement. Cording and Hansmire [8] defined the ground loss as the volume of soil that is displaced across the perimeter of a tunnel. Whatever the soil type, it is convenient to express the volume loss in terms of the volume of the surface settlement trough $V_{s}$ expressed as a percentage fraction of the excavated area of the tunnel per unit length of tunnel constructed, i.e. for a circular tunnel. The percentage volume loss $V_{l}$ is defined as follows,

$$
V_{l}=\frac{V_{s}}{V_{t}} \cdot 100 \%
$$

where $\quad V_{s}=$ settlement trough volume

$V_{t} \quad=$ tunnel opening volume $\left(\pi \cdot R^{2}\right)$

$R \quad=$ radius of the tunnel 
Based on the shape of the normal distribution curve, [3] showed that the maximum settlement, $S_{v, \max }$ can be given by,

$$
S_{v, \max }=\frac{0.314 . V L \cdot D^{2}}{i}
$$

where $D=$ diameter of the tunnel

$S_{v, \max }=$ maximum settlement occurring above the tunnel axis

The settlement at various points of the trough is then given by,

$$
S_{v}(y)=S_{v, \max } \exp \left(\frac{-y^{2}}{2 i^{2}}\right)
$$

where $y=$ the horizontal distance from the tunnel centre line

$i \quad=$ the horizontal distance from the tunnel centre line to the point of inflection of the settlement trough

The definition is illustrated in Figure 1.

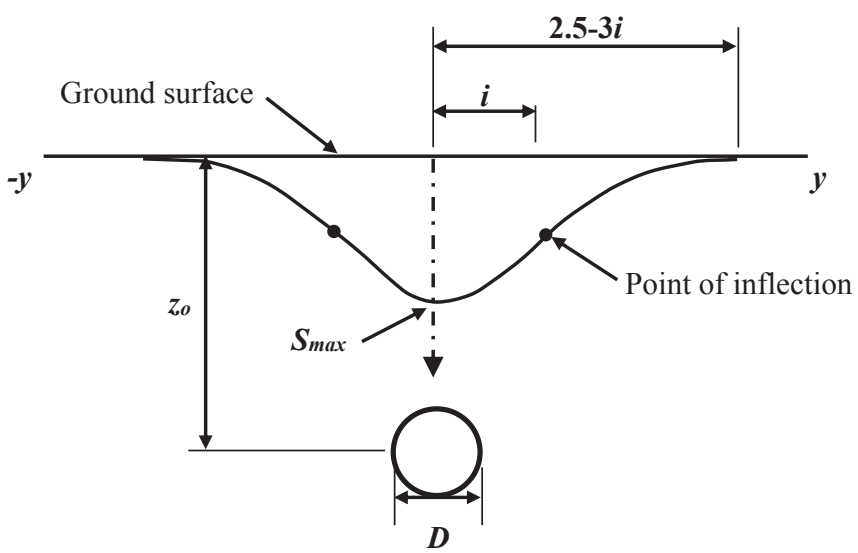

Fig. 1. Definition of settlement trough of Gaussian form

It should be noted that Equation (3) is normally applied to the immediate surface settlements associated with tunnel construction. Additional post-construction settlement due to consolidation tends to cause wider settlement troughs and this complicates the interpretation of the settlement data. Softer clays are more susceptible to appreciable consolidation settlement, which often develops rapidly and can be difficult to separate from the immediate construction settlement; this may partly explain the observation by Peck [3] that wider settlement troughs are observed above tunnels in soft clays than in stiff clays.

In addition to the settlement volume $V_{s}$ one has to consider the ground loss $V_{l}$ which is the volume of the ground that has deformed into the tunnel after the tunnel has been constructed. For tunnelling in undrained soil (constant volume), the settlement volume is more or less equal to the ground loss, but the settlement volume trends to be somewhat smaller for water-drained excavations. The dilation and swelling due to the unloading may result in soil expansion, such that $V_{s}<V_{l}$. However, differences tend to remain small and it can be assumed that $V_{s}=V_{l}$. Nevertheless, it should be noted that the trough width parameter is independent with volume loss [9]. 


\section{Method of analysis}

The main objective of study is to investigate, using numerical method, the arbitrary relationship of the trough width parameter for different soil types in terms of its effective shear strength parameters $\left(c^{\prime}, \varnothing^{\prime}\right)$ and stiffness parameter $\left(E^{\prime}\right)$. It is anticipated that this will provide an insight into the significance of each parameter to the estimation of trough width parameter for empirical calculation of tunnelling-induced settlement.

With the advancement in numerical modelling capability, Finite Element (FE) modelling has become very popular tool in prediction of tunnelling-induced ground settlement [10]. For simplified and reliable modelling, it is reasonable to assume a plane strain or two-dimensional (2-D) model for long tunnel section in studying tunnellinginduced settlements. In this study, the numerical analyses were carried out for a basic problem with the following assumptions:

- The tunnel diameter $D=6 \mathrm{~m}$ and the depth of tunnel axis $z_{o}=15 \mathrm{~m}$ below ground.

- The tunnel lining is of $275 \mathrm{~mm}$ thick with concrete grade G60, simulated as linear elastic impermeable element with the following parameters: Density $=24 \mathrm{kN} / \mathrm{m}^{3}, E=$ $37,000 \mathrm{MPa}, v=0.2$.

- The soil is a deep homogenous incompressible layer, assumed to be in drained condition.

- Groundwater is considered at ground level.

There are different methods possible for simulating the shield tunnelling in 2-D FE model. In this study, contraction method [11] of ground loss resulted from contracted tunnel lining is adopted in the computer program PLAXIS. The model domain measures $80 \mathrm{~m}$ wide and $40 \mathrm{~m}$ high and is consisted of total 346 elements and 2913 nodes as shown in Figure 2. The soil was modelled using Hardening Soil (HS) Model which is formulated in the framework of hardening multi-surface plasticity [12]. In the HS model, the total strains were calculated using as stress-dependent stiffness, different for both virgin loading and un/reloading. The boundary conditions were fixed by standard fixities, where side vertical boundaries were fixed in horizontal $x$-direction but free to move vertically, while the bottom boundary was restrained from any movement in all directions. Drained material was used. The HS model soil parameters are presented in Table 1. To account for the typical soil types which are rather cohesive or loose in nature, the dilatation was neglected by assuming that the angle of dilatancy of the soil is equal to zero.

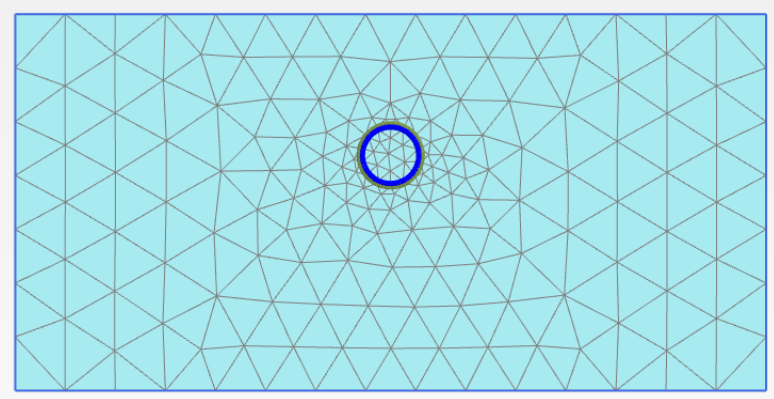

Fig. 2. Two-dimensional finite element mesh 
Table 1. HS model soil parameters

\begin{tabular}{|l|l|l|l|l|l|}
\hline Parameter & Unit & Description & Parameter & Unit & Description \\
\hline$\gamma_{b}$ & $\mathrm{kN} / \mathrm{m}^{3}$ & 19 & $c_{\text {ref }}$ & $\mathrm{kN} / \mathrm{m}^{2}$ & various, see Table 2 \\
\hline$v$ & & 0.3 & $\phi(\mathrm{phi})$ & $\circ$ & various, see Table 2 \\
\hline$K_{o}$ & & $1-\sin \phi$ & $\psi(\mathrm{psi})$ & $\circ$ & 0 \\
\hline$E_{50}^{\text {ref }}$ & $\mathrm{MN} / \mathrm{m}^{2}$ & various, see Table 2 & Power $(\mathrm{m})$ & & 0.5 \\
\hline$E_{\text {oed }}^{\text {ref }}$ & $\mathrm{MN} / \mathrm{m}^{2}$ & $=E_{50}^{\text {ref }}$ & $\begin{array}{l}\text { Reference } \\
\text { pressure }\end{array}$ & $\mathrm{kN} / \mathrm{m}^{2}$ & 100 \\
\hline$E_{\text {ur }}^{\text {ref }}$ & $\mathrm{MN} / \mathrm{m}^{2}$ & $=3 E_{50}^{r e f}$ & & \\
\hline
\end{tabular}

The analysis for this study typically involved the following steps:

Step 1 - initialization of the in-situ stresses using $K_{o}$ procedure

Step 2 - excavation of the soil and dewatering of the tunnel and subsequent installation of its lining

Step 3 - applying a contraction to the tunnel lining to simulate the volume loss

The surface settlement trough due to stress redistributions in the surrounding soil as a result of the contraction procedure is extracted from the PLAXIS output.

\section{Parametric study}

To bridge the gap of knowledge, parametric study was carried out by varying the effective shear strength parameters and soil stiffness to identify parameter(s) which have a significant influence on the settlement trough width. The representative wide-ranging soil parameters for the various soil types commonly found in Klang Valley, as shown in Table 2, was investigated. Unless otherwise specified, a line contraction of the tunnel lining of $1 \%$ was assigned which corresponds approximately to a value loss of $1 \%$ of the tunnel volume. The soil stiffness was kept constant throughout the analyses with variable shear strength parameters and vice-versa. This set of analyses will be repeated with different volume loss to evaluate the consistency of the result findings. The relationship between the volume loss at tunnel face and the volume of surface settlement trough will also be presented.

Table 2. Typical range of soil parameters subject to parametric study

\begin{tabular}{|c|c|c|c|}
\hline Soil parameters & Study case & Constant value & Variable value \\
\hline \multirow{2}{*}{$\begin{array}{l}\text { Effective shear } \\
\text { strength } \\
\text { parameters }\end{array}$} & Case $1-\varnothing^{\prime}$ & $\begin{array}{l}c^{\prime}=1 \mathrm{kPa} \\
E^{\prime}=21 \mathrm{MPa}\end{array}$ & $\begin{array}{l}\sigma^{\prime}=20^{\circ}, 22^{\circ}, 23^{\circ}, 25^{\circ}, 27^{\circ}, 28^{\circ}, 29^{\circ}, 30^{\circ}, \\
31^{\circ}, 32^{\circ}, 33^{\circ}, 34^{\circ}, 35^{\circ}, 36^{\circ}, 38^{\circ}, 40^{\circ}\end{array}$ \\
\hline & Case $2-c^{\prime}$ & $\begin{array}{l}\varnothing^{\prime}=30^{\circ} \\
E^{\prime}=21 \mathrm{MPa}\end{array}$ & $\begin{array}{l}c^{\prime}=0,1,2,3,4,5,6,7,8,9,10,15,20 \\
25 \mathrm{kPa}\end{array}$ \\
\hline Soil stiffness & Case $3-E^{\prime}$ & $\begin{array}{l}c^{\prime}=1 \mathrm{kPa} \\
\varnothing^{\prime}=30^{\circ}\end{array}$ & $E^{\prime}=20,30,50,75,100,150,200,250 \mathrm{MPa}$ \\
\hline
\end{tabular}

Acknowledging the limitations of each numerical modelling is essential in the study. Following are some of the limitations observed:

- Another sensitive parameter that plays an important role would be the coefficient of earth pressure at rest $K_{o}$.

- The recent stress history of the soil, described by anisotropic unloading or re-loading, has an important effect on the predicted surface settlement trough [13].

It was suggested that the choice of an appropriate value of $K$ may depend on whether the tunnel is above or below the water table specifically in granular ground [3]. 


\section{Results and discussion}

\subsection{Relationship between trough width parameter and effective shear strength parameters}

Figure 3 shows the relation between the trough width parameter $K$ and effective friction angle $\varnothing^{\prime}$ with constant cohesion $c^{\prime}=1 \mathrm{kPa}$. For comparison purpose, the results of various effective cohesion (constant $\varnothing^{\prime}=30^{\circ}$ ) is also plotted in the same figure. In both cases, the soil was modelled with constant soil stiffness $E^{\prime}$ of $21 \mathrm{MPa}$.

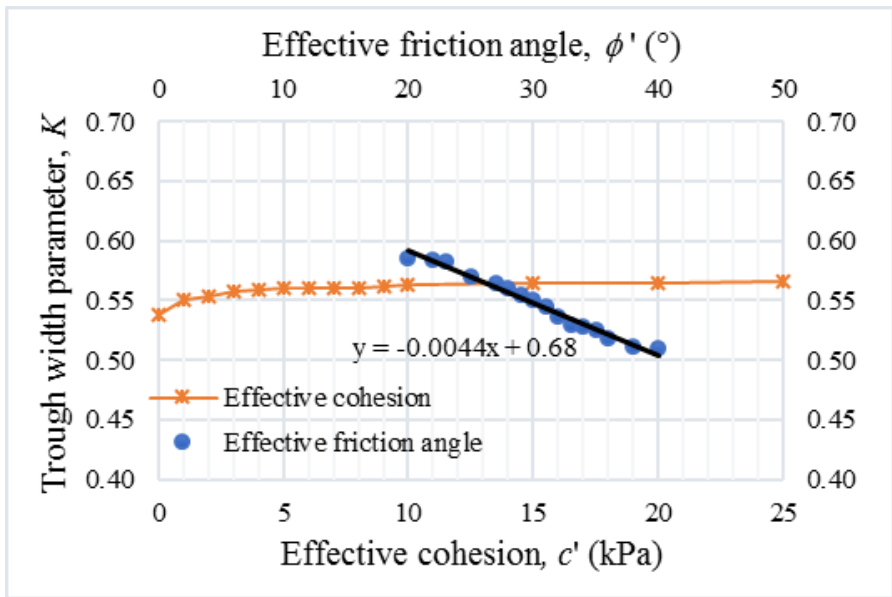

Fig. 3. Relationship between trough width parameter and effective shear strength parameters

Generally, it can be seen that the different cohesion values did not cause significant variation to the trough width parameter, in particular for high cohesion values. This implies that settlement trough is not sensitive to the typical range of cohesion values. However, the value of trough width parameter was found to be decreasing appreciably when the friction angle is increasing. Assuming a same amount of volume loss (e.g. $V_{t}=1 \%$ in this study), the slightly lower $K$ value would result in narrower settlement profile and larger maximum settlement; whereas higher $K$ value results in wider settlement profiles but smaller maximum settlement.

\subsection{Relationship between trough width parameter and soil stiffness}

Figure 4 shows the value of trough width parameter $K$ varying with the soil stiffness, $E$ '. The figure represents the parameter which correspond to typical soil type of effective shear strength parameters, $c^{\prime}=1 \mathrm{kPa}$ and $\varnothing^{\prime}=30^{\circ}$ at tunnel volume loss of $1 \%$. Apparently, the value of trough width parameter was observed similarly to be decreasing when the soil stiffness is higher than $50 \mathrm{MPa}$. But, the change of trough width parameter was in reversing trend for an increasing soil stiffness, from $20 \mathrm{MPa}$ to $50 \mathrm{MPa}$. 


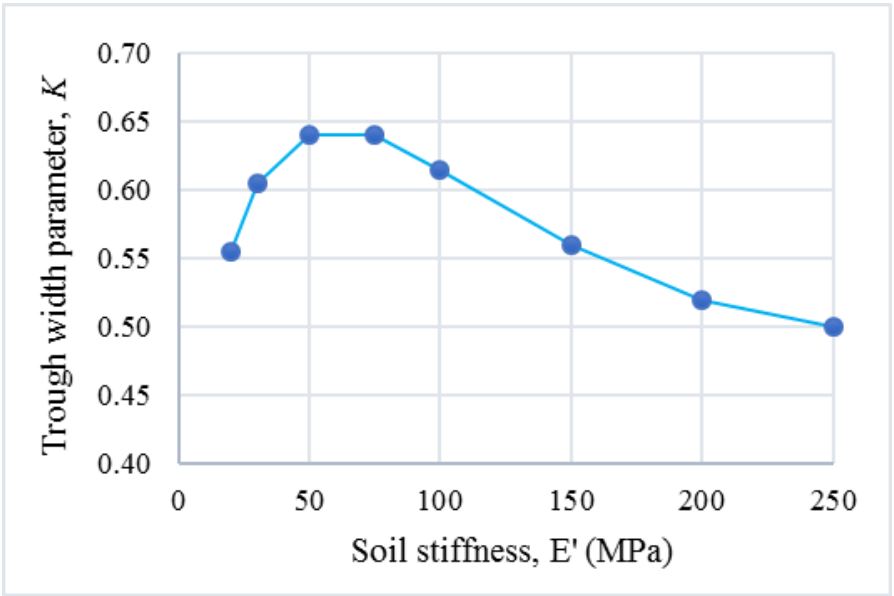

Fig. 4. Relationship between trough width parameter and soil stiffness

The numerical models all predict considerably wider troughs as compared to typical value $K=0.5$ recommended by several design guidance notes. The wider settlement trough predicted by 2-D FE analyses may be linked to the assumed coefficient of earth pressure at rest $K_{o}$. Reducing $K_{o}$ locally either side of the tunnel to account for unloading associated with 3-D effects leads to narrower, more realistic settlement troughs being predicted by 2-D FE analyses [14-15]. Cording [16] has noted that the width of the transverse settlement trough above tunnels in granular soils depends to some extent on the magnitude of settlement, with larger settlements tending to cause a narrower overall width of the trough consistent with the "chimney" mechanism in sand. Point should be noted that the general recommendation of $K=0.25$ for tunnels in sands and gravels is based on the database confined to shallow tunnels in sands with depths to axis level in the range of $6-10 \mathrm{~m}$. A more recent data compiled by Mair and Taylor [17] exhibit rather scatter for tunnels in sands and gravels. Despite two of the data points show considerably wider troughs, the majority of the data fall within the bounds of $K=0.25$ and $K=0.45$ with a mean line of $K=$ 0.35 .

In all cases, as shown in Figure 5, the settlement volume $V_{s}$ became lesser than the volume (ground) loss $V_{l}$ induced at tunnel face owing to the support from 'arching effect' and possible dilation due to unloading. This is similar to the observation by previous literatures $[8,18]$.

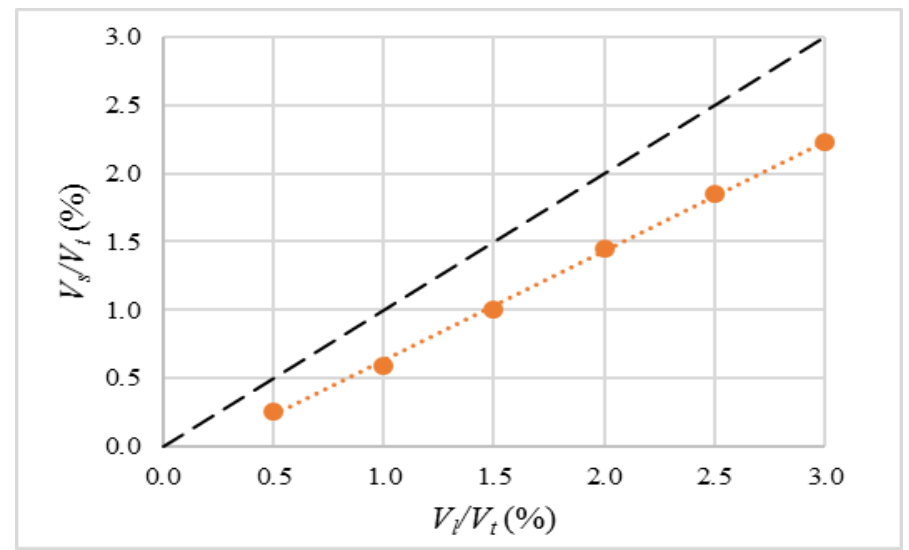

Fig. 5. Relationship between volume loss and volume of settlement trough 
Based on the results of the parametric study, it has been analysed that, within the range of parameters examined, the trough width parameter for typical tunnel depth $z_{o}=15 \mathrm{~m}$ may be approximated as follows:

$$
K=0.68-0.0044 \varnothing
$$

where $K=$ trough width parameter

$\varnothing=$ effective friction angle ranges from $20^{\circ}$ to $40^{\circ}$

The trough width parameter obtained from Equation (4) is used for empirical calculation of tunnelling-induced settlement using the Gaussian function for Klang Valley tunnelling project.

\section{Conclusions}

This paper studies the arbitrary relationship of the trough width parameter for different soil types in terms of its effective shear strength parameters and soil stiffness. From the numerical analyses, it can be concluded that the settlement trough having the form of the cumulative probability curve illustrated in Figure 1 is generally reasonable. The numerical study reveals the majority of cases $K>0.5$ for the typical soil types encountered in the Klang Valley of Malaysia and hence confirms the conclusion of O'Reilly and New [4] that $K=0.5$ is appropriate for practical purposes.

The factors which may have significant influence on the trough width parameter are identified to include effective friction angle and soil stiffness. Effective friction angle is of major importance in many cases with an appreciable pattern of decreasing $K$ value is evident when the friction angle is increasing. The general observation is that the surface settlement profile where the tunnel is in higher frictional soil indicate slightly narrower profiles than would be obtained if the tunnel was only in cohesive soil. There is also evidence that higher soil stiffness causing a narrowing of the surface settlement profile, as implied by Figure 4. This is probably a consequence of the stiffer soil layer in the region of the tunnel reduced influence of movements, which can affect the overall settlement trough. However, the increment in $K$ value was very marginal and hence it can be concluded that there is a negligible effect of soil cohesion on trough width parameter.

Simple equation is presented for estimating appropriate value of trough width parameter considering the effective friction angle of soil and may be used in practice to assess the surface settlement trough due to tunnelling operations. Effort to continually build up the field database to further refine the deduced relationship for the surface settlement trough width parameter is in progress over the course of construction for Klang Valley MRT tunnels.

\section{References}

1. F. Martos, Concerning an approximate equation of the subsidence trough and its time factors, Proc. of International Strata Control Congress, Liepzig, 191-205 (1958)

2. B. Schmidt, Settlements and ground movements associated with tunnelling in soil, $\mathrm{PhD}$ Thesis, University of Illinois (1969)

3. R.B. Peck, Deep excavation and tunnelling in soft ground - State-of-the-Art Report, Proc. of 7th Int. Conf. on SMFE, Mexico, 225-290 (1969)

4. M.P. O'Reilly, B.M. New, Settlement above tunnels in the United Kingdom - their magnitude and prediction, Tunnelling 82, 173-181 (IMM, London, 1982) 
5. W.J. Rankin, Ground movements resulting from urban tunnelling, Proc. of Conf. Eng. Geol., Underground Movements, London Geological Society, Nottingham, 79-92 (1988)

6. K. Fujita, On the surface settlements caused by various methods of shield tunnelling, Proc. 11th Int. Conf. on Soil Mechanics and Foundation Engineering, 4, 609-610 (1981)

7. L.M. Lake, W.J. Rankin, J. Hawley, Prediction and effects of ground movements caused by tunnelling in soft ground beneath urban areas, CIRIA Project Report 30, (Construction Industry Research and Information Association, London, 1992)

8. E.J. Cording, W.H. Hansmire, Displacements around soft ground tunnels, General Report, 5th Pan-American Conference on Soil Mechanics and Foundations Engineering, Buenos Aires, 571-632 (1975)

9. Y.H. Zhang, W.M. Cham, J. Kumarasamy, Volume loss caused by tunnelling of Circle Line projects, Underground Singapore 2011 (2011)

10. E. Namazi, H. Mohamad, E. Jorat, M. Hajihassani, Investigation on the effects of twin tunnel excavations beneath a road underpass, 16 (D), 441-450 (2011)

11. P.A. Vermeer, R. Brinkgreve, PLAXIS Version Manual (Balkema, Rotterdam, 1993)

12. T. Schanz, P.A. Vermeer, P.G. Bonnier, The hardening soil model: Formulation and verification, Beyond 2000 in Computational Geotechnics - 10 Years of PLAXIS, (Balkema, Rotterdam, 1999)

13. S.E. Stallebrass, V. Jovicic, R.N. Taylor, The influence of recent stress history on ground movements around tunnels, Pre-failure Deformation of Geomaterials (eds S. Shibuya, T. Mitachi, and S. Miura), 1, 615-620 (Balkema, 1994)

14. T.I. Addenbrooke, Numerical analysis of tunnelling in stiff clay, $\mathrm{PhD}$ Thesis, Imperial College of Science Technology and Medicine (1996)

15. E. Namazi, H. Mohamad, A.B.H. Kueh, M. Hajihassani, et al., Ground behaviour around a tunnel using various soil models, Electronic Journal of Geotechnical Engineering, 17 (E), 609-622 (2012)

16. E.J. Cording, Control of ground movements around tunnels in soil, General Report, 9th Pan-American Conference on Soil Mechanics and Foundation Engineering, Chile, (1991)

17. R.J. Mair, R.N. Taylor, Theme lecture: Bored tunnelling in the urban environment, Proceedings of the 14th Int. Conf. on Soil Mech. and Found. Eng., Hamburg, 4, 23532385 (1997)

18. T.I. Addenbrooke, D.M. Potts, A.M. Puzrin, Géotechnique, The influence of prefailure soil stiffness on the numerical analysis of tunnel construction, 47 (3), 693-712 (1997) 